\title{
Relationship between exercise desaturation and pulmonary haemodynamics in COPD patients
}

\author{
C.C. Christensen*,\#, M.S. Ryg", A. Edvardsen*,\#, O.H. Skjønsberg*
}

Relationship between exercise desaturation and pulmonary haemodynamics in COPD patients. C.C. Christensen, M.S. Ryg, A. Edvardsen, O.H. Skjønsberg. (C)ES Journals Ltd 2004.

ABSTRACT: Pulmonary hypertension (PH) in patients with chronic obstructive pulmonary disease (COPD) has traditionally been explained as an effect of hypoxaemia. Recently, other mechanisms, such as arterial remodelling caused by inflammation, have been suggested. The aim of this study was to investigate whether exercise-induced PH (EIPH) could occur without concurrent hypoxaemia, and whether exercise-induced hypoxaemia (EIH) was regularly accompanied by increased pulmonary artery pressure or pulmonary vascular resistance index (PVRI).

Pulmonary haemodynamics in 17 patients with COPD of varying severity, but with no or mild hypoxaemia at rest, were examined during exercise equivalent to the activities of daily living (ADL) and exhaustion.

EIPH occurred in $65 \%$ of the patients during ADL exercise. Pulmonary arterial pressure during exercise was negatively correlated with arterial oxygen tension, but EIPH was not invariably accompanied by hypoxaemia. Conversely, EIPH was not found in all patients with EIH. The resting PVRI was negatively correlated with arterial oxygen tension during ADL exercise, but an elevated PVRI without EIH occurred in $35 \%$ of the patients.

In conclusion, exercise-induced pulmonary hypertension occurred during exercise equivalent to the activities of daily living in chronic obstructive pulmonary disease patients with no or mild hypoxaemia at rest. Although pulmonary artery pressure and arterial oxygen tension were negatively correlated during exercise, a consistent relationship between hypoxaemia and pulmonary hypertension could not be demonstrated. This may indicate that mechanisms other than hypoxaemia contribute significantly in the development of pulmonary hypertension in these patients.

Eur Respir J 2004; 24: 580-586.
*Dept of Pulmonary Medicine, Ullevaal University Hospital, Oslo, and "Glittreklinikken, Hakadal, Norway.

\author{
Correspondence: C.C. Christensen \\ Glittreklinikken \\ 1488 Hakadal \\ Norway \\ Fax: 4767075344 \\ E-mail: ca.chris@online.no
}

Keywords: Chronic obstructive pulmonary disease

exercise

hypoxaemia

pulmonary hypertension

pulmonary vascular resistance

right heart catheterisation

Received: October 222003

Accepted after revision: May 122004
Development of pulmonary hypertension (PH) frequently occurs in patients with chronic obstructive pulmonary disease (COPD) [1]. PH is associated with increased morbidity [1], and BURROws et al. [2] showed that the survival of COPD patients was inversely related to their pulmonary vascular resistance index (PVRI). WeITZENBLUM et al. [3] found similar results with regard to pulmonary arterial pressure (Ppa). Longstanding PH is associated with impaired right ventricular function [4], and, in a 15-yr follow-up study, TRAVER et al. [5] observed that the presence of cor pulmonale was strongly linked to reduced survival in patients with COPD.

The pathogenesis of PH in COPD patients has not been fully elucidated. Chronic hypoxaemia has traditionally been used to explain the development of $\mathrm{PH}$ in COPD patients [6]. Hypoxaemia induces vasoconstriction of pulmonary arteries, and persisting vasoconstriction may induce chronic changes in the arterial wall [7]. Both clinical and experimental studies show similarities between changes in the pulmonary vasculature of humans and animals exposed to hypoxic conditions and vascular changes in COPD patients [8]. It has also been suggested that repeated episodes of hypoxaemia, occurring during sleep or exercise, may promote pulmonary vasoconstriction and subsequent remodelling of the pulmonary arteries, leading to persistent PH [6]. Since the early 1990s, the theory of hypoxaemia as the major inducer of $\mathrm{PH}$ in COPD patients has been challenged. Structural and functional changes in the pulmonary arteries have been observed in normoxic patients in the initial stages of COPD, and it has been suggested that remodelling of the arterial wall can be induced by low-grade inflammation. This could be related to cigarette smoking $[1,9]$, or be part of general disease-related systemic and pulmonary inflammation [10]. Interestingly, signs of remodelling of pulmonary arteries have been found in smokers who have not yet developed COPD [11].

Changes in the pulmonary circulation, resulting from remodelling of the pulmonary arterial walls, may start several years before $\mathrm{PH}$ is apparent at rest [1]. This remodelling, leading to an increased PVRI, may cause elevated Ppa, particularly during exercise [12]. Thus it has been suggested that exercise testing might be useful in the early diagnosis of $\mathrm{PH}[1,12,13]$. The aim of the current investigation was to study the relationship between hypoxaemia and pulmonary haemodynamics during exercise in patients with COPD of varying severity, but with no or only mild hypoxaemia at rest. It was of interest whether exercise-induced PH (EIPH) could occur without a corresponding decrease in arterial oxygen tension $\left(\mathrm{Pa}, \mathrm{O}_{2}\right)$, and, conversely, whether exercise-induced hypoxaemia (EIH) was regularly accompanied by an increase in PVRI or Ppa. Seventeen patients equipped with an 
indwelling Swan-Ganz catheter in the pulmonary artery were examined during both exercise equivalent to the activities of daily living (ADL) and maximal exercise. The relationship between pulmonary haemodynamics and spirometric results, single-breath transfer factor of the lung for carbon monoxide (TL,CO), pulmonary capillary volume and aerobic capacity was also studied.

\section{Material and methods}

\section{Study subjects}

Seventeen patients from the outpatient clinic of the Dept of pulmonary medicine (Ullevaal University Hospital, Oslo, Norway) were selected for the study. The patients, nine females and eight males, suffered from COPD according to the criteria of the American Thoracic Society [14]. Forced expiratory volume in one second (FEV1) ranged 19-54\% of the predicted value, resting $\mathrm{Pa}_{2} \mathrm{O}_{2}$ was $>9 \mathrm{kPa}$ (table 1) and resting arterial carbon dioxide tension was $<6.0 \mathrm{kPa}$ in all patients. The patients included five current smokers and twelve exsmokers. None of the patients showed clinical signs of left ventricular dysfunction as assessed by dynamic isotope investigation, or coexisting medical problems that might influence their physical capacity. At the time of testing, all patients were in a stable phase of their disease. All used daily bronchodilating medication, and one subject was also taking a low dose of prednisolone $\left(5 \mathrm{mg} \cdot \mathrm{day}^{-1}\right)$. The drug regimen was unchanged during the last 4 weeks prior to the study. A restrictive ventilatory defect in patients with reduced forced vital capacity (FVC) was excluded, either by chest radiography, by measurement of total lung capacity or on clinical grounds.

The Regional Ethics Committee of East Norway (Health Region 1) approved the study, and written informed consent was obtained from all participants.

Table 1.-Demographics and pulmonary function in chronic obstructive pulmonary disease patients

\begin{tabular}{|c|c|c|}
\hline & \multicolumn{2}{|c|}{ Value } \\
\hline & Measured & $\%$ pred \\
\hline \multicolumn{3}{|l|}{ Demographics } \\
\hline Age yrs & $54.8 \pm 9.1$ & \\
\hline Height $\mathrm{cm}$ & $170 \pm 9$ & \\
\hline Weight kg & $69.5 \pm 17.8$ & \\
\hline \multicolumn{3}{|l|}{ Resting values } \\
\hline FVC L & $2.4 \pm 0.7$ & $64 \pm 16$ \\
\hline FEV1 L & $1.0 \pm 0.3$ & $35 \pm 10$ \\
\hline$T \mathrm{~L}, \mathrm{CO} \mathrm{mmol} \cdot \mathrm{min}^{-1} \cdot \mathrm{kPa}^{-1}$ & $5.6 \pm 2.0$ & $66 \pm 22$ \\
\hline$Q \mathrm{pc} \mathrm{mL}$ & $44.7 \pm 14.6$ & $59.0 \pm 17.8$ \\
\hline$P \mathrm{a}, \mathrm{O}_{2} \mathrm{kPa}$ & $10.6 \pm 1.1$ & \\
\hline $\mathrm{Sa}, \mathrm{O}_{2} \%$ & $94.6 \pm 2.0$ & \\
\hline$P a, \mathrm{CO}_{2} \mathrm{kPa}$ & $5.0 \pm 0.5$ & \\
\hline \multicolumn{3}{|l|}{ Exercise data } \\
\hline$V^{\prime} \mathrm{O}_{2}, \max \mathrm{mL} \cdot \min ^{-1} \cdot \mathrm{kg}^{-1}$ & $16.6 \pm 5.0$ & \\
\hline
\end{tabular}

Data are presented as mean \pm SD. FVC: forced vital capacity; FEV1: forced expiratory volume in one second; $T \mathrm{~L}, \mathrm{CO}$ : single-breath transfer factor of the lung for carbon monoxide; $Q$ pc: pulmonary capillary blood volume; $\mathrm{Pa}, \mathrm{O}_{2}$ : arterial oxygen tension; $\mathrm{Sa}, \mathrm{O}_{2}$ : arterial oxygen saturation; $\mathrm{Pa}, \mathrm{CO}_{2}$ : arterial carbon dioxide tension; $V^{\prime} \mathrm{O}_{2}$, max: peak oxygen uptake; $\%$ pred: percentage of the predicted value.

\section{Lung function and treadmill tests}

The patients underwent pulmonary function and ergospirometric testing on a treadmill 2-4 days prior to right heart catheterisation. Treadmill ergometry, as opposed to the cycle ergometry used during catheterisation (see below), was used because walking seems to be a better way of characterising the patients' aerobic capacity [15]. The lung function tests included spirometry, TL,CO and pulmonary capillary blood volume measurements, performed using Jaeger MasterLab equipment (Erich Jaeger $\mathrm{GmbH}$, Würzburg, Germany) according to American Thoracic Society criteria [14]. Ergospirometry was performed on a treadmill to the patients' symptom-limited maximum. The treadmill speed was started at $1.2 \mathrm{~km} \cdot \mathrm{h}^{-1}$ and increased by $0.6 \mathrm{~km} \cdot \mathrm{h}^{-1}$ every 2 min until a maximum of $4.8 \mathrm{~km} \cdot \mathrm{h}^{-1}$ was reached. For further increases in workload, the speed was kept constant and the inclination increased by $1.5 \% \cdot \mathrm{min}^{-1}$. Peak ventilation, oxygen uptake $\left(V^{\prime} \mathrm{O}_{2}\right)$ and carbon dioxide output $\left(V^{\prime} \mathrm{CO}_{2}\right)$ were measured in a breath-by-breath mode using an Oxycon Champion metabolic cart (Erich Jaeger $\mathrm{GmbH}$ ). Oxygen saturation was continuously monitored by pulse oximetry (SatTrak; SensorMedics, Yorba Linda, CA, USA).

\section{Study protocol}

All treadmill and bicycle exercise tests were performed between 09:00 and 13:00 h, after the patients had taken their usual daily medication. Twelve-lead electrocardiography was performed prior to the experiment, and cardiac rhythm was monitored continuously thereafter. Arterial blood samples were drawn from an indwelling catheter in the radial artery. Normoxia was defined as a $P$ a, $\mathrm{O}_{2}$ of $>10.0 \mathrm{kPa}$ and mild hypoxaemia as a $\mathrm{Pa}, \mathrm{O}_{2}$ of $8.1-10.0 \mathrm{kPa}$ [16]. A Swan-Ganzballoon-directed four-channel thermodilution catheter (Swan Ganz 7-F Thermodilution Catheter; Baxter Healthcare, Irvine, CA, USA) was inserted percutaneously into an antecubital vein. The catheter was positioned in the right atrium, right ventricle and pulmonary artery.

Haemodynamic measurements included right atrial pressure $(P$ ra $)$, mean $P$ pa and pulmonary capillary wedge pressure $(P$ pcw $)$. In the supine position, the zero point of the intravascular pressures was $10 \mathrm{~cm}$ above the surface of the back, and, in the sitting position, the zero point was set to the intersection of the left midclavicular line and the fifth intercostal space. The mean $P$ pa was measured over a short period, during which the patients were asked to stop breathing, but not to close the glottis. The pressures were recorded through the catheter using a Baxter Truwave disposable pressure transducer (Edwards Lifesciences, LLC, Irvine, CA, USA) and a Mingograf 7 (Siemens-Elema, Solna, Sweden). EIPH was defined as a $P$ pa of $>30 \mathrm{mmHg}$ [4]. One patient had a $P$ ra of $11 \mathrm{mmHg}$ in the supine position at rest; in the remaining $16, P$ ra was $\leqslant 8 \mathrm{mmHg}$. In the sitting position at rest, none had a $P$ ra of $>8 \mathrm{mmHg}$. Sampling of arterial and mixed central venous blood was performed anaerobically, and the samples were placed on ice and analysed within 15 min (Ciba Corning 865; Bayer Diagnostics Manufacturing (Sudbury) Ltd, Sudbury, UK, and ABL 525; Radiometer, Copenhagen, Denmark). Gas exchange was measured using Oxycon Champion equipment at rest and during cycling exercise during the catheterisation experiments, and a stable $V^{\prime} \mathrm{CO}_{2} / V^{\prime} \mathrm{O}_{2}$ ratio (respiratory exchange ratio (RER)) was obtained before blood sampling. Cardiac output was determined from the $V^{\prime} \mathrm{O}_{2}$ and arterial and mixed venous oxygen content, according to the direct Fick's principle [17]. From these parameters, pulmonary vascular resistance was 
calculated and corrected for body surface area (PVRI). A PVRI of $>200 \mathrm{dyn} \cdot \mathrm{s} \cdot \mathrm{cm}^{-5} \cdot \mathrm{m}^{2}$ was defined as elevated [7].

All measurements were obtained during the last minute of each workload. Measurements in the supine position were performed only at rest. In the sitting position, measurements were performed during both rest and incremental bicycle exercise until the symptom-limited maximum (Ergoline 800 ergometer cycle; Erich Jaeger $\mathrm{GmbH}$ ), starting at $25 \mathrm{~W}$, being defined as equivalent to ADL exercise, and increasing by $10 \mathrm{~W}$ every $5 \mathrm{~min}$. At the start of the exercise, an operator cranked the pedals by hand in order to assist the patient in obtaining a stable pedalling frequency and avoid the initial inertia. Two patients managed only unloaded exercise for $5 \mathrm{~min}$, whereas 11 patients performed at a workload of $>25 \mathrm{~W}$. Subjective effort was assessed using the Borg rate of perceived exertion scale [18].

\section{Statistical analysis}

Data are expressed as mean \pm SD or SEM. Relationships between variables were assessed using Pearson's correlation coefficients. Differences between situations were assessed with repeated-measures analysis of variance, followed by the Tukey-Kramer honestly significant difference test for pairwise comparisons. Two-tailed $\mathrm{p}$-values of $<0.05$ were considered significant.

\section{Results}

The patients' characteristics and results of lung function tests are presented in table 1 . FVC was $64 \pm 16 \%$ of the predicted value, whereas FEV1 was $35 \pm 10 \%$ pred. Peak $V^{\prime} \mathrm{O}_{2} \quad\left(V^{\prime} \mathrm{O}_{2}, \max \right)$ during treadmill exercise was $16.6 \pm 5.0 \mathrm{~mL} \cdot \mathrm{min}^{-1} \cdot \mathrm{kg}^{-1}$ (table 1). The ventilatory reserve, determined as the percentage difference between ventilation during maximal exercise and $35 \times \mathrm{FEV} 1$, was greatly reduced $(5.2 \pm 18.6 \%)$, a sign of ventilatory limitation. The maximal workload during bicycle exercise was $32 \pm 15 \mathrm{~W}$, ranging $0-55 \mathrm{~W}$.

There was no significant difference in $\mathrm{Pa}_{2} \mathrm{O}_{2}$ between the supine and sitting position at rest $(10.5 \pm 0.3$ versus $10.4 \pm 0.3 \mathrm{kPa}$ ) (fig. 1a). From rest to ADL exercise, a modest decrease in $\mathrm{Pa}, \mathrm{O}_{2}$ was observed (10.4 \pm 0.3 versus $9.7 \pm 0.4 \mathrm{kPa} ; \mathrm{p}<0.05)$, but there was no significant change from ADL to maximal exercise for those patients in whom the maximal workload was $>25 \mathrm{~W}$.

Resting $P$ pa in the supine position was $19.9 \pm 4.5 \mathrm{mmHg}$, and no significant difference in $P$ pa at rest was observed between the supine and sitting positions. $P$ pa increased significantly during ADL exercise $(35.0 \pm 2.2 \mathrm{mmHg}$; $\mathrm{p}<0.001$ ) (fig. 1b), and was $>30 \mathrm{mmHg}$ in $11(65 \%)$ patients at this workload. In the 11 patients in whom maximal exercise was $>25 \mathrm{~W}, P$ pa increased further to $39.2 \pm 3.1 \mathrm{mmHg}$ $(\mathrm{p}<0.05)$. Resting $P$ pcw in the supine position was $7.7 \pm 0.7 \mathrm{mmHg}$, and there was no significant change to the sitting position. $P$ pcw increased significantly during ADL exercise $(10.8 \pm 0.9 \mathrm{mmHg} ; \mathrm{p}<0.01)$. No further increase in $P$ pcw was observed for workloads of $>25 \mathrm{~W}$.

The resting PVRI in the supine position was $321 \pm 28$ $\mathrm{dyn} \cdot \mathrm{s} \cdot \mathrm{cm}^{-5} \cdot \mathrm{m}^{2}$, and increased to $469 \pm 33 \mathrm{dyn} \cdot \mathrm{s} \cdot \mathrm{cm}^{-5} \cdot \mathrm{m}^{2}$ while sitting $(\mathrm{p}<0.001)$ (fig. 1c). No further change in PVRI was observed during either ADL or maximal exercise.

The cardiac index $(\mathrm{CI})$ decreased from the supine to the sitting position $\left(3.2 \pm 0.2\right.$ versus $\left.2.4 \pm 0.1 \mathrm{~L} \cdot \mathrm{min}^{-1} \cdot \mathrm{m}^{-2} ; \mathrm{p}<0.001\right)$ (fig. 1d), and increased to $4.4 \pm 0.2 \mathrm{~L} \cdot \mathrm{min}^{-1} \cdot \mathrm{m}^{-2}$ during ADL
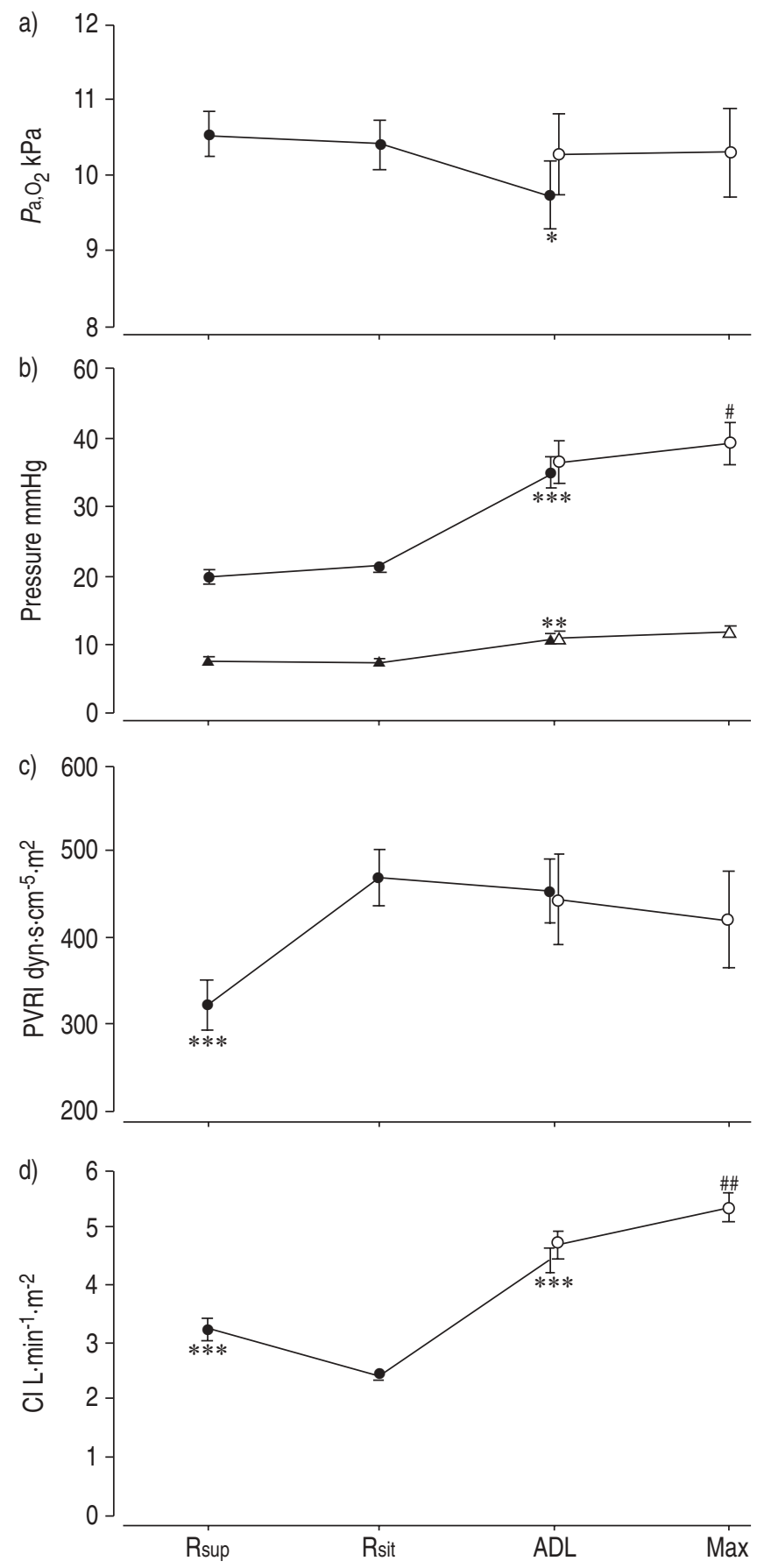

Fig. 1. - a) Brachial arterial oxygen tension $\left(\mathrm{Pa}_{\mathrm{a}} \mathrm{O}_{2}\right)$, b) pulmonary arterial pressure $(\bigcirc, \boldsymbol{0})$ and pulmonary capillary wedge pressure $(\triangle$, $\Delta)$, c) pulmonary vascular resistance index (PVRI), and d) cardiac index (CI) in 17 patients at supine (Rsup) and sitting rest (Rsit), and during exercise equivalent to the activities of daily living (ADL) ( $\bullet$ $\boldsymbol{\Delta})$, and in 11 patients with a maximal workload of $>25 \mathrm{~W}$ during ADL and maximal exercise (Max) $(\bigcirc, \triangle) . *$ : $<<0.05 ; * *: p<0.01 ; * * *$ : $\mathrm{p}<0.001$ versus sitting rest; \#: $\mathrm{p}<0.05$; \#\#: $\mathrm{p}<0.001$ versus $\mathrm{ADL}$ exercise.

exercise $(\mathrm{p}<0.001)$. During maximal $(>25 \mathrm{~W})$ exercise $(\mathrm{n}=11)$, CI increased further to $5.3 \pm 0.3 \mathrm{~L} \cdot \mathrm{min}^{-1} \cdot \mathrm{m}^{-2}(\mathrm{p}<0.01)$.

Individual data for $V^{\prime} \mathrm{O}_{2}, \mathrm{RER}, \mathrm{Pa}, \mathrm{O}_{2}$ and haemodynamic parameters are presented in table 2 .

During ADL exercise, $P$ pa was negatively correlated with $P \mathrm{a}, \mathrm{O}_{2}(\mathrm{r}=-0.57, \mathrm{p}<0.05)$, but four $(24 \%)$ patients with a $\mathrm{Pa}, \mathrm{O}_{2}$ of $>10 \mathrm{kPa}$ had $P$ pa of $>30 \mathrm{mmHg}$, and two (12\%) patients 
Table 2. - Pulmonary function and haemodynamic parameters at rest ${ }^{\#}$ and during exercise ${ }^{\sigma}$ in individual chronic obstructive pulmonary disease patients

\begin{tabular}{|c|c|c|c|c|c|c|c|c|c|}
\hline Patient No. & Situation & $\begin{array}{l}\text { Workload } \\
\text { W }\end{array}$ & $\begin{array}{c}V^{\prime} \mathrm{O}_{2} \\
\mathrm{~mL} \cdot \mathrm{min}^{-1}\end{array}$ & RER & $\begin{array}{c}\mathrm{Pa}_{\mathrm{a}, \mathrm{O}_{2}} \\
\mathrm{kPa}\end{array}$ & $\underset{\mathrm{L} \cdot \mathrm{min}^{-1} \cdot \mathrm{m}^{-2}}{\mathrm{CI}}$ & $\begin{array}{c}P \mathrm{pa} \\
\mathrm{mmHg}\end{array}$ & $\begin{array}{c}P \text { pcw } \\
\mathrm{mmHg}\end{array}$ & $\begin{array}{c}\text { PVRI } \\
\text { dyn } \cdot \mathrm{s} \cdot \mathrm{cm}^{-5} \cdot \mathrm{m}^{2}\end{array}$ \\
\hline \multirow[t]{4}{*}{1} & Supine rest & 0 & 188 & 0.69 & 10.40 & 3.0 & 18 & 7 & 296 \\
\hline & Sitting rest & 0 & 197 & 0.77 & 10.94 & 2.1 & 23 & 8 & 569 \\
\hline & ADL exercise & 25 & 624 & 0.84 & 11.71 & 4.2 & 37 & 13 & 457 \\
\hline & Maximal exercise & 55 & 1115 & 0.91 & 10.26 & 6.3 & 48 & 14 & 435 \\
\hline \multirow[t]{4}{*}{2} & Supine rest & 0 & 222 & 0.80 & 9.56 & 3.0 & 27 & 11 & 427 \\
\hline & Sitting rest & 0 & 275 & 0.77 & 9.82 & 3.1 & 25 & 10 & 383 \\
\hline & ADL exercise & 25 & 883 & 0.86 & 10.62 & 6.3 & 35 & 14 & 267 \\
\hline & Maximal exercise & 35 & 1027 & 0.89 & 11.75 & 6.6 & 36 & 12 & 293 \\
\hline \multirow[t]{4}{*}{3} & Supine rest & 0 & 186 & 0.80 & 10.57 & 2.1 & 20 & 5 & 561 \\
\hline & Sitting rest & 0 & 220 & 0.75 & 10.16 & 2.1 & 27 & 10 & 654 \\
\hline & ADL exercise & 25 & 775 & 0.87 & 7.27 & 4.5 & 55 & 11 & 790 \\
\hline & Maximal exercise & 35 & 804 & 0.90 & 6.93 & 4.5 & 60 & 11 & 880 \\
\hline \multirow[t]{4}{*}{4} & Supine rest & 0 & 234 & 0.79 & 11.22 & 3.1 & 14 & 8 & 156 \\
\hline & Sitting rest & 0 & 212 & 0.84 & 11.22 & 1.7 & 19 & 8 & 517 \\
\hline & ADL exercise & 25 & 650 & 0.93 & 9.79 & 3.5 & 32 & 10 & 500 \\
\hline & Maximal exercise & 35 & 840 & 0.93 & 9.78 & 4.1 & 39 & 15 & 472 \\
\hline \multirow[t]{3}{*}{5} & Supine rest & 0 & 141 & 0.88 & 12.37 & 3.2 & 20 & 7 & 320 \\
\hline & Sitting rest & 0 & 203 & 0.81 & 11.90 & 1.7 & 21 & 6 & 691 \\
\hline & ADL exercise & $0^{+}$ & 346 & 0.85 & 10.84 & 2.6 & 30 & 10 & 615 \\
\hline \multirow[t]{3}{*}{6} & Supine rest & 0 & 270 & 0.86 & 11.48 & 4.4 & 18 & 7 & 202 \\
\hline & Sitting rest & 0 & 321 & 0.82 & 12.35 & 3.5 & 19 & 12 & 160 \\
\hline & ADL exercise & 25 & 882 & 0.82 & 10.60 & 5.7 & 26 & 6 & 282 \\
\hline \multirow[t]{4}{*}{7} & Supine rest & 0 & 308 & 0.83 & 9.14 & 4.0 & 27 & 11 & 318 \\
\hline & Sitting rest & 0 & 358 & 0.78 & 9.28 & 2.9 & 23 & 8 & 407 \\
\hline & ADL exercise & 25 & 1200 & 0.83 & 8.62 & 5.2 & 43 & 15 & 427 \\
\hline & Maximal exercise & 35 & 1282 & 0.83 & 8.62 & 6.2 & 43 & 15 & 362 \\
\hline \multirow[t]{4}{*}{8} & Supine rest & 0 & 252 & 0.75 & 9.48 & 3.9 & 20 & 11 & 185 \\
\hline & Sitting rest & 0 & 342 & 0.77 & 11.54 & 2.9 & 25 & 12 & 361 \\
\hline & ADL exercise & 25 & 759 & 0.77 & 9.89 & 4.2 & 33 & 15 & 345 \\
\hline & Maximal exercise & 35 & 844 & 0.79 & 10.17 & 5.3 & 36 & 17 & 285 \\
\hline \multirow[t]{4}{*}{9} & Supine rest & 0 & 184 & 0.78 & 11.66 & 2.1 & 22 & 9 & 497 \\
\hline & Sitting rest & 0 & 257 & 0.68 & 9.47 & 2.3 & 25 & 7 & 628 \\
\hline & ADL exercise & 25 & 804 & 0.78 & 8.00 & 4.7 & 52 & 10 & 720 \\
\hline & Maximal exercise & 55 & 1052 & 0.89 & 7.83 & 5.2 & 49 & 10 & 603 \\
\hline \multirow[t]{4}{*}{10} & Supine rest & 0 & 210 & 0.83 & 12.56 & 5.0 & 18 & 7 & 177 \\
\hline & Sitting rest & 0 & 329 & 0.81 & 12.26 & 3.0 & 22 & 7 & 406 \\
\hline & ADL exercise & 25 & 720 & 0.88 & 12.76 & 4.8 & 27 & 8 & 315 \\
\hline & Maximal exercise & 35 & 925 & 0.95 & 13.07 & 6.0 & 31 & 9 & 296 \\
\hline \multirow[t]{4}{*}{11} & Supine rest & 0 & 215 & 0.83 & 11.94 & 3.3 & 15 & 4 & 269 \\
\hline & Sitting rest & 0 & 244 & 0.86 & 10.72 & 2.7 & 20 & 6 & 411 \\
\hline & ADL exercise & 25 & 765 & 0.95 & 12.46 & 5.6 & 33 & 13 & 288 \\
\hline & Maximal exercise & 35 & 903 & 1.01 & 12.88 & 5.8 & 35 & 11 & 332 \\
\hline \multirow[t]{4}{*}{12} & Supine rest & 0 & 245 & 0.75 & 11.39 & 3.5 & 15 & 5 & 226 \\
\hline & Sitting rest & 0 & 255 & 0.85 & 12.48 & 2.3 & 15 & 5 & 354 \\
\hline & ADL exercise & 25 & 824 & 0.89 & 11.72 & 4.6 & 23 & 4 & 327 \\
\hline & Maximal exercise & 45 & 894 & 0.96 & 11.95 & 4.4 & 23 & 9 & 254 \\
\hline \multirow[t]{3}{*}{13} & Supine rest & 0 & 234 & 0.82 & 8.83 & 2.4 & 21 & 10 & 359 \\
\hline & Sitting rest & 0 & 296 & 0.82 & 8.84 & 2.4 & 19 & 7 & 400 \\
\hline & ADL exercise & 25 & 669 & 0.88 & 7.67 & 3.9 & 45 & 16 & 591 \\
\hline 14 & Supine rest & 0 & 226 & 0.81 & 9.79 & 3.2 & 30 & 13 & 428 \\
\hline & Sitting rest & 0 & 263 & 0.82 & 9.22 & 2.1 & 24 & 9 & 574 \\
\hline & ADL exercise & 25 & 667 & 0.88 & 7.40 & 3.5 & 38 & 15 & 526 \\
\hline 15 & Supine rest & 0 & 195 & 0.85 & 9.30 & 2.4 & 20 & 8 & 400 \\
\hline & Sitting rest & 0 & 216 & 0.86 & 8.40 & 1.6 & 17 & 6 & 561 \\
\hline & ADL exercise & 25 & 821 & 0.83 & 7.41 & 4.1 & 30 & 10 & 390 \\
\hline 16 & Supine rest & 0 & 228 & 0.71 & 9.97 & 2.9 & 18 & 6 & 333 \\
\hline & Sitting rest & 0 & 278 & 0.85 & 9.54 & 2.3 & 21 & 7 & 478 \\
\hline & ADL exercise & 25 & 711 & 0.84 & 10.29 & 4.2 & 31 & 8 & 436 \\
\hline & Maximal exercise & 35 & 850 & 0.87 & 10.09 & 4.6 & 31 & 8 & 396 \\
\hline 17 & Supine rest & 0 & 213 & 0.79 & 9.27 & 3.4 & 15 & 2 & 309 \\
\hline & Sitting rest & 0 & 268 & 0.83 & 8.72 & 2.9 & 17 & 2 & 411 \\
\hline & ADL exercise & $0^{+}$ & 411 & 0.79 & 8.29 & 3.7 & 25 & 6 & 410 \\
\hline
\end{tabular}

$V^{\prime} \mathrm{O}_{2}$ : oxygen uptake; RER: respiratory exchange ratio; $P \mathrm{a}, \mathrm{O}_{2}$ : arterial oxygen tension; CI: cardiac index; $P$ pa: pulmonary arterial pressure; $P$ pcw: pulmonary capillary wedge pressure; PVRI: pulmonary vascular resistance index; ADL: activities of daily living. "\#: supine and sitting; ": ADL exercise, as well as maximal exercise in those patients whose maximal workload was $>25 \mathrm{~W} ;^{+}$: unloaded exercise. 

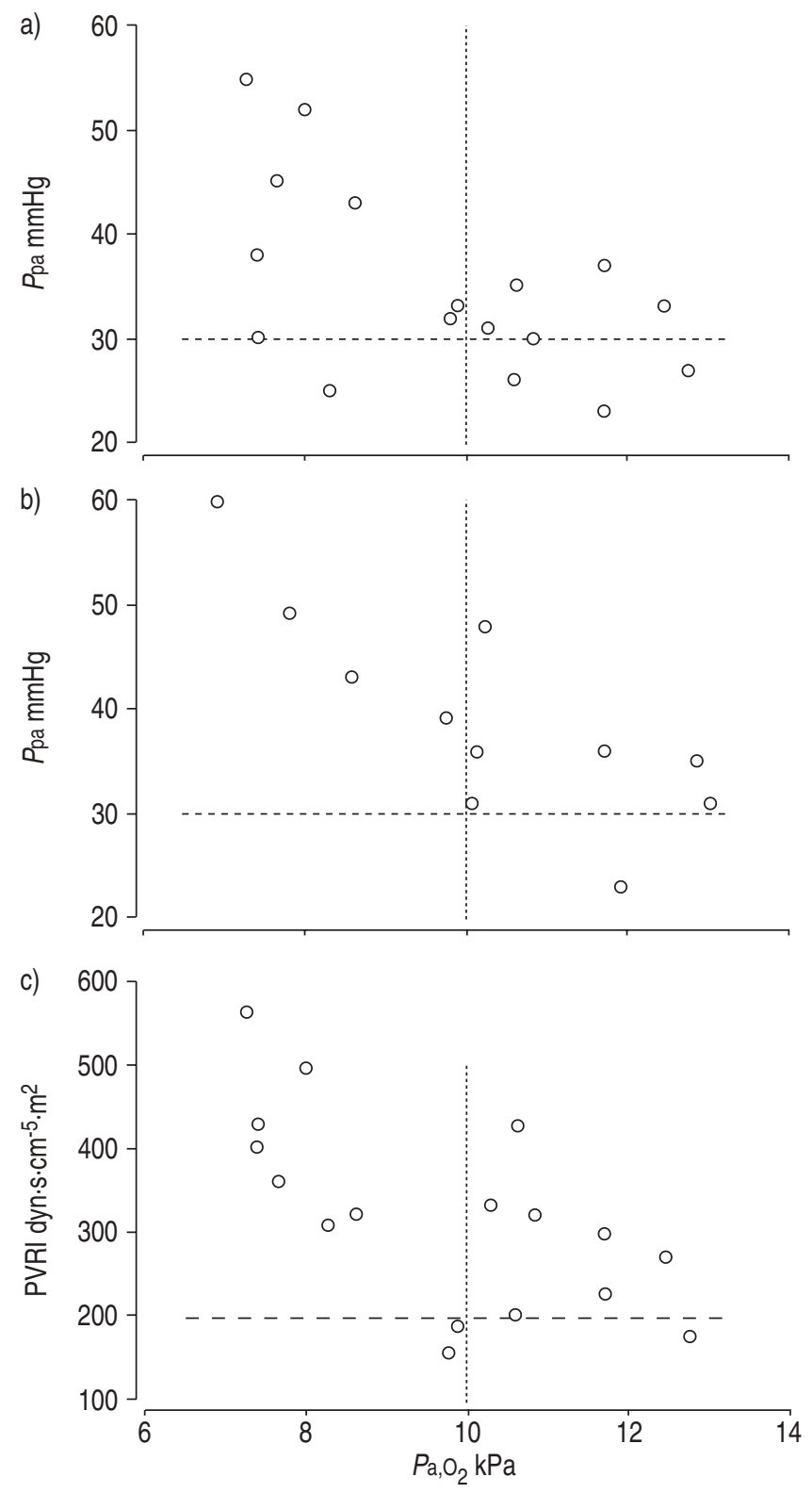

Fig. 2. - Relationship between: a, b) pulmonary arterial pressure $(P \mathrm{pa})$ and arterial oxygen tension $\left(P_{\left.\mathrm{a}, \mathrm{O}_{2}\right)}\right)$ during: a) exercise equivalent to the activities of daily living (ADL); and b) maximal exercise; and c) pulmonary vascular resistance index (PVRI) at supine rest and $\mathrm{Pa}_{\mathrm{a}} \mathrm{O}_{2}$ during ADL exercise (cut-offs: $\cdots \cdots$ : hypoxaemia; ------: exerciseinduced pulmonary hypertension; - - - -: PVRI).

with a $P$ a, $\mathrm{O}_{2}$ of $<10 \mathrm{kPa}$ had $P$ pa of $\leqslant 30 \mathrm{mmHg}$ (fig. 2a). Likewise, at a maximal exercise of $>25 \mathrm{~W}, P$ pa was negatively correlated with $\mathrm{Pa}, \mathrm{O}_{2}(\mathrm{r}=-0.80, \mathrm{p}<0.05)$, but six $(35 \%)$ patients with a $\mathrm{Pa}, \mathrm{O}_{2}$ of $>10 \mathrm{kPa}$ had $P$ pa of $>30 \mathrm{mmHg}$ (fig. 2b). However, at maximal exercise, all patients with a $\mathrm{Pa}, \mathrm{O}_{2}$ of $<10 \mathrm{kPa}$ had $P$ pa of $>30 \mathrm{mmHg}$.

PVRI in the supine position was negatively correlated with $\mathrm{Pa}, \mathrm{O}_{2}$ during ADL exercise $(\mathrm{r}=-0.65, \mathrm{p}<0.01)$. Six $(35 \%)$ patients with a supine resting PVRI of $>200 \mathrm{dyn} \cdot \mathrm{s} \cdot \mathrm{cm}^{-5} \cdot \mathrm{m}^{2}$ had $\mathrm{Pa}, \mathrm{O}_{2}$ of $>10 \mathrm{kPa}$ both at rest and during ADL exercise (fig. 2c).

Ppa during ADL exercise was correlated with PVRI in the supine position $(\mathrm{r}=0.66, \mathrm{p}<0.01)$ (fig. 3a). During supine rest, there was a negative correlation between $\mathrm{CI}$ and PVRI $(\mathrm{r}=-0.75, \mathrm{p}<0.001)$ (fig. 3b). Neither resting PVRI nor $P$ pa


Fig. 3.- Relationship between pulmonary vascular resistance index (PVRI) at supine rest and: a) pulmonary arterial pressure $(P \mathrm{pa})$ during exercise equivalent to the activities of daily living; and b) cardiac index (CI).

during ADL or maximal exercise were significantly correlated with FEV1, TL,CO, capillary volume or blood gas tensions at rest, or with $V^{\prime} \mathrm{O}_{2}$, max using treadmill exercise. $P \mathrm{a}, \mathrm{O}_{2}$ at supine or sitting rest was not significantly correlated with either Ppa or PVRI in these situations.

\section{Discussion}

In the present study, a significant increase in $P$ pa during both ADL and maximal exercise was demonstrated in COPD patients with no or mild hypoxaemia at rest. In spite of only minor exercise-induced desaturation in these patients, the $P$ pa exceeded the levels defined for EIPH in $65 \%$ of the patients during ADL exercise. Exercise $P$ pa was negatively correlated with $\mathrm{Pa}, \mathrm{O}_{2}$, but EIPH was not invariably accompanied by hypoxaemia, i.e. some of the patients with the lowest $\mathrm{Pa}, \mathrm{O}_{2}$ showed no EIPH, and some of the patients without significant oxygen desaturation showed EIPH. Supine resting PVRI was negatively correlated with $\mathrm{Pa}, \mathrm{O}_{2}$ during ADL exercise, but $35 \%$ of the patients had PVRIs above normal values without concomitant EIH.

Remodelling of pulmonary arteries starts early in the course of COPD [1, 11], and increased PVRI has been considered the primary haemodynamic abnormality in the development of PH in COPD [12]. There is no general consensus as to what value of PVRI should be considered 
pathological; NAEIJE and BARBERA [7] referred to $200 \mathrm{dyn} \cdot \mathrm{s} \cdot \mathrm{cm}^{-5} \cdot \mathrm{m}^{2}$ as an upper limit of normal, whereas CHEMLA et al. [4] quoted values ranging 240-480 dyn $\cdot \mathrm{s} \cdot \mathrm{cm}^{-5} \cdot \mathrm{m}^{2}$ as upper limits. In the present subjects, PVRI in the supine position was $>200,>240$ and $>480 \mathrm{dyn} \cdot \mathrm{s} \cdot \mathrm{cm}^{-5} \cdot \mathrm{m}^{2}$ in 12 , nine and two patients, respectively. This is an interesting finding, considering the absence of hypoxaemia, suggesting that the elevated PVRIs were not dependent on resting hypoxaemia in these patients. Likewise, the increase in PVRI from the supine to the sitting position also occurred without a concomitant change in $\mathrm{Pa}_{2} \mathrm{O}_{2}$. Since the patients with the highest PVRIs also showed the highest $P$ pa during exercise, the authors interpret this as indicating the start of a development towards persistent $\mathrm{PH}$ in these individuals, in accordance with the findings of KESSLER et al. [13] showing that EIPH is predictive of the development of persistent PH. It is worth noting that the majority of the present patients developed $\mathrm{PH}$ during ADL exercise. Thus these patients probably experience several episodes of $\mathrm{PH}$ during the day, which might promote arterial remodelling and development of $\mathrm{PH}$. The absence of $\mathrm{PH}$ at rest in most of the present patients may be explained by a low CI in the patients with high PVRIs [12]. The relatively large increase in $P$ pa at low workloads in the present patients was related to an unchanged PVRI during exercise, and those patients with highest PVRIs at rest also had the highest $P$ pa during exercise. This is in agreement with previous findings in COPD patients with established $\mathrm{PH}$, but differs from normal subjects, where the PVRI usually decreases during exercise [12, 19-21]. Increased $P$ pa could conceivably be due to air trapping in parts of the lung. Air trapping may lead to increased alveolar pressure, and this increased pressure may be mechanically transmitted to the pulmonary circulation [22], although the relationship between intrathoracic pressure and $P$ pcw is not always straightforward [23]. In the present experiment, the increase in $P$ pcw could explain only $22 \%$ of the total increase in $P$ pa during ADL exercise. Thus most of the increase in $P$ pa from rest to ADL exercise seems to be explained by a near doubling of CI without a concomitant decrease in PVRI, in agreement with previous studies on COPD patients [24].

In contrast to what has been described for persistent $\mathrm{PH}$, no correlation was found between PVRI or Ppa on the one hand, and spirometric values, TL,CO or resting blood gas tensions on the other. With regard to resting blood gas tensions, the reason for this difference might be that remodelling of pulmonary arteries can occur before significant hypoxaemia is evident. The lack of correlation between pulmonary haemodynamic parameters and both $T \mathrm{~L}, \mathrm{CO}$ and capillary volume does not suggest a primary effect of destruction of the capillary bed on the development of $\mathrm{PH}$, in agreement with results from human and experimental animal studies [25-28].

The correlation between $\mathrm{Pa}, \mathrm{O}_{2}$ during exercise and resting PVRI might suggest that repeated episodes of hypoxaemia during ADL induce pulmonary vasoconstriction and subsequently arterial remodelling and an increased PVRI. WeITZENBLUM et al. [26] found a significant partial correlation between $P$ pa and $P$ a, $\mathrm{O}_{2}$ (at constant $\mathrm{CI}$ ) in COPD patients during supine cycling, indicating an effect of hypoxaemia on the PVRI. However, PH has primarily been associated with resting $\mathrm{Pa}, \mathrm{O}_{2}$ of $<\sim 8 \mathrm{kPa}$ [20]. In the present study, all patients had resting $P \mathrm{a}, \mathrm{O}_{2}$ well above this threshold, and still showed increased PVRI and resting $P$ pa in the upper limit of the normal range. Furthermore, none of the patients were severely hypoxaemic during ADL or maximal exercise. Thus it may be questioned whether EIH of the degree observed in the present study would have caused significant pulmonary arterial vasoconstriction and PH. Conversely, remodelling of pulmonary arteries may occur in the absence of hypoxaemia, possibly caused by low-grade inflammation related to both cigarette smoking and the chronic pulmonary disease per se [1,9]. Pulmonary arterial remodelling is associated with a higher degree of ventilation/perfusion mismatch [9], which might result in arterial desaturation, particularly during exercise, when increased influx of blood of low oxygen tension accentuates the effect of mismatch [29]. Therefore, it is difficult to distinguish whether the observed negative correlation between exercise $P$ pa and exercise $P$ a, $\mathrm{O}_{2}$ was caused by hypoxaemic vasoconstriction of the pulmonary arteries, or whether the modest EIH observed in some of the present patients was an effect of already established changes in the arterial walls with increased PVRI. The finding of EIPH in the absence of EIH might support the latter explanation, although it should be borne in mind that the number of patients showing this pattern is limited.

In conclusion, exercise-induced pulmonary hypertension in chronic obstructive pulmonary disease patients with no or only mild hypoxaemia at rest occurred during exercise equivalent to the activities of daily living, indicating repeated episodes of pulmonary hypertension occurring throughout the day. No correlation between exercise pulmonary arterial pressure and forced expiratory volume in one second, singlebreath transfer factor of the lung for carbon monoxide, pulmonary capillary volume, resting blood gas tensions or aerobic capacity was observed. Exercise-induced pulmonary hypertension may occur in the absence of significant oxygen desaturation, and even though there was a negative correlation between pulmonary arterial pressure and arterial oxygen tension during exercise, a consistent relationship between hypoxaemia and pulmonary hypertension could not be demonstrated. Although the number of patients is limited, this may indicate that mechanisms other than hypoxaemia contribute significantly in the development of pulmonary hypertension in these patients.

\section{References}

1. Barberà JA, Peinado VI, Santos S. Pulmonary hypertension in chronic obstructive pulmonary disease. Eur Respir J 2003; 21: 892-905.

2. Burrows B, Kettel LJ, Niden AH, Rabinowitz M, Diener CF. Patterns of cardiovascular dysfunction in chronic obstructive lung disease. $N$ Engl J Med 1972; 286: 912-918.

3. Weitzenblum E, Sautegeau A, Erhart M, Mammosser M, Hirth C, Roegel E. Long-term course of pulmonary arterial pressure in chronic obstructive pulmonary disease. Am Rev Respir Dis 1984; 130: 993-998.

4. Chemla D, Castelain P, Hervé P, Lecarpentier Y, Brimioulle S. Haemodynamic evaluation of pulmonary hypertension. Eur Respir J 2002; 20: 1314-1331.

5. Traver GA, Cline MG, Burrows B. Predictors of mortality in chronic obstructive pulmonary disease. A 15-year follow-up study. Am Rev Respir Dis 1979; 119: 895-902.

6. Weitzenblum E. The pulmonary circulation and the heart in chronic lung disease. Monaldi Arch Chest Dis 1994; 49: 231234.

7. Naeije R, Barbera JA. Pulmonary hypertension associated with COPD. Crit Care 2001; 5: 286-289.

8. Ward M, Milledge J, West J. Cardiovascular system. In: High Altitude Medicine and Physiology. London, Chapman \& Hall Medical, 1995; pp. 126-154.

9. Barberà JA, Riverola A, Roca J. Pulmonary vascular abnormalities and ventilation-perfusion relationship in mild chronic obstructive pulmonary disease. Am J Respir Crit Care Med 1994; 149: 423-429.

10. Agustí AGN, Noguera A, Sauleda J, Sala E, Pons J, Busquets X. Systemic effects of chronic obstructive pulmonary disease. Eur Respir J 2003; 21: 347-360. 
11. Peinado VI, Barberà JA, Ramírez J, et al. Endothelial dysfunction in pulmonary arteries of patients with mild COPD. Am J Physiol 1998; 274: L908-L913.

12. Rogers TK, Howard P. Pulmonary hemodynamics and physical training in patients with chronic obstructive pulmonary disease. Chest 1992; 101: 289S-292S.

13. Kessler R, Faller M, Weitzenblum E, et al. "Natural history" of pulmonary hypertension in a series of 131 patients with chronic obstructive lung disease. Am J Respir Crit Care Med 2001; 164: 219-224.

14. American Thoracic Society. Lung function testing: selection of reference values and interpretative strategies. Am Rev Respir Dis 1991; 144: 1202-1218.

15. Christensen CC, Ryg M, Refvem OK, Skjønsberg $\mathrm{OH}$. Effect of exercise mode on oxygen uptake and blood gases in COPD patients. Respir Med 2004; 98: 661-668.

16. Coker RK, Partridge MR. Assessing the risk of hypoxia in flight: the need for more rational guidelines. Eur Respir $J$ 2000; 15: 128-130.

17. Cournand A, Riley RL, Breed ES, Baldwin E de F, Richards DW. Measurements of cardiac output in man using technique of catheterization of the right auricle or ventricle. $J$ Clin Invest 1945; 24: 106-116.

18. Borg G. Psychophysical bases of perceived exertion. Med Sci Sports Exerc 1982; 14: 377-381.

19. Grossman W, Braunwald E. Pulmonary hypertension. In: Braunwald E, ed. Heart Disease. A Textbook of Cardiovascular Disease. Philadelphia, PA, Saunders, 1992; pp. 790816.

20. Horsfield K, Segel N, Bishop JM. The pulmonary circulation in chronic bronchitis at rest and during exercise breathing air and $80 \%$ oxygen. Clin Sci 1968; 43: 473-483.

21. Jezek V, Schrijen F, Sadoul P. Right ventricular function and pulmonary hemodynamics during exercise in patients with chronic obstructive bronchopulmonary disease. Cardiology 1973; 58: 20-31.

22. Butler J, Schrijen F, Henriques A, Polu J-M, Albert K Cause of the raised wedge pressure on exercise in chronic obstructive pulmonary disease. Am Rev Respir Dis 1988; 138 : $350-359$.

23. Lockhart A, Tzareva M, Nader F, Leblanc P, Schrijen F, Sadoul P. Elevated pulmonary artery wedge pressure at rest and during exercise in chronic bronchitis: fact or fancy. Clin Sci 1969; 37: 503-517.

24. Lockhart A, Nader F, Tzareva M, Schrijen F. Comparative effects of exercise and isocapnic voluntary hyperventilation on pulmonary haemodynamics in chronic bronchitis and emphysema. Eur J Clin Invest 1970; 1: 69-76.

25. Keller CA, Shepard JW Jr, Chun DS, Vasques P, Dolan GF. Pulmonary hypertension in chronic obstructive pulmonary disease. Multivariate analysis. Chest 1986; 90: 185-192.

26. Weitzenblum E, el-Gharbi T, Vandevenne A, Bleger A, Hirth $\mathrm{C}$, Oudet P. Le comportement hemodynamique pulmonaire au cours de l'exercise musculaire dans la bronchite chronique non "decompensee". [Pulmonary haemodynamic changes during muscular exercise in nondecompensated chronic bronchitis]. Bull Physiopathol Respir (Nancy) 1972; 8: 49-71.

27. Scharf SM, Iqbal M, Keller C, Criner G, Lee S, Fessler HE. Hemodynamic characterization of patients with severe emphysema. Am J Respir Crit Care Med 2002; 166: 314-322.

28. Yamato H, Sun JP, Churg A, Wright JL. Guinea pig pulmonary hypertension caused by cigarette smoke cannot be explained by capillary bed destruction. J Appl Physiol 1997; 82: 1644-1653.

29. Wagner PD. Ventilation-perfusion matching during exercise. Chest 1992; 101: 192S-198S. 